\title{
Resource base of blue cod Parapercis colias subpopulations in marginal fjordic habitats is linked to chemoautotrophic production
}

\author{
S. R. Wing, N. A. Beer, L. Jack* \\ Department of Marine Science, University of Otago, PO Box 56, Dunedin 9054, New Zealand
}

\begin{abstract}
Metapopulations are often distributed across habitat patches with distinct differences in nutritional resources. We investigate individual variability in diet among subpopulations of blue cod Parapercis colias across productivity gradients within Fiordland, New Zealand. $\delta^{13} \mathrm{C}$ and $\delta^{15} \mathrm{~N}$ of basal organic matter, including phytoplankton, macroalgae, terrestrial detritus and the chemosymbiont-harbouring clam Solemya parkinsonii, were collected. P. colias from inner and outer fjord sites within 5 fjords were analysed for proportion of diet comprising S. parkinsonii, and $\delta^{13} \mathrm{C}$ and $\delta^{15} \mathrm{~N}$ of muscle tissue. Relative abundance of photoautotrophic organic matter was quantified from surveys of chl $a$ and abundance of common kelp Ecklonia radiata. Information on mussel beds was collected to characterise potential for benthic-pelagic coupling. A mass balance model using $\delta^{13} \mathrm{C}$ and $\delta^{15} \mathrm{~N}$ was used to estimate trophic level and proportion of organic matter from chemosynthesis for individual blue cod. Blue cod from the inner fjords had more variable use of organic matter originating from photoautotrophic versus chemoautotrophic sources than those from outer fjord regions. This was consistent with greater occurrence of $S$. parkinsonii in stomachs of blue cod from the inner fjords. Abundance of phytoplankton and occurrence of mussels statistically explained $87 \%$ of the variability in proportion of organic matter originating from chemosynthesis. These data provide an important example of variation in basal organic matter sources among subpopulations within a marine metapopulation. Our results demonstrate the importance of organic matter produced from chemosynthesis in coastal food webs providing a mechanism for maintenance of high trophic level consumers in marginal habitats.
\end{abstract}

KEY WORDS: Chemoautotrophy · Food web · Fjord · Reef fish · Stable isotopes · Trophic level · Metapopulation

Resale or republication not permitted without written consent of the publisher

\section{INTRODUCTION}

Theory suggests that multi-trophic level food webs distributed along gradients in primary productivity are subject to strong thresholds that result in abrupt boundaries for distributions of high trophic level consumers (Oksanen et al. 1981). In these systems, however, a high degree of migration or 'spillover' of individuals from high to low productivity habitat can result in maintenance of subpopulations in marginal habitat, which may lead to local overexploitation of resources and barren habitat conditions (Oksanen 1990). In these situations, the effective range of a population may extend into habitats with a relatively poor resource base (Pulliam 1988, Liu et al. 2011). These observations have important implications for understanding the distribution of metapopulations along gradients in primary production and for understanding mechanisms for maintenance of subpopulations of high trophic level consumers in marginal, low productivity habitats. A key scientific requirement, therefore, is to understand how the resource base for 
subpopulations, as indicated by diversity of basal organic matter sources, changes across environmental gradients.

Metapopulation dynamics of many coastal invertebrates and fishes may be strongly influenced by habitat quality and the effects of the nutritional environment on local growth and reproductive output (e.g. Sanford \& Menge 2007, Jack \& Wing 2010). Though subpopulations can be linked by larval dispersal over relatively large distances, site fidelity by adult reef fish may result in large differences in diet, growth and egg production among habitats (Gust et al. 2002, Lawton et al. 2010). Accordingly, at this local population level, the food webs supporting generalist reef fish may reflect the relative availability of basal organic matter sources (Vander Zanden \& Vadeboncoeur 2002, McLeod et al. 2010a). As resources become rare, or habitat quality changes, variability in diet among individuals may increase (Fry et al. 1999, Vander Zanden et al. 2010). In this case, specialisation or diversification in resource use at the individual level may be a primary mechanism for increases in niche breadth and expansion of metapopulations across marginal habitat along a gradient of diminishing resources (Bolnick et al. 2003).

Increases in dietary diversity may result in dampening of temporal variability inherent to any one food source leading to temporal stability of a resource base, or a 'portfolio effect' (Tilman et al. 1997, Doak et al. 1998). At the base of this process is the temporal variability inherent to guilds of primary producers. In the marine environment, macroalgae and phytoplankton represent 2 basal organic matter sources with differences in seasonal variability. Seasonal phytoplankton blooms result in large and distinct fluxes of organic matter into marine systems. These fluxes are highly variable in both space and time and can result in boom and bust cycles in primary consumers. In contrast, macroalgae represent a more temporally stable organic matter source and, in the case of kelp forests, represent a constantly available accumulated biomass (Jack \& Wing 2011).

An additional stabilising process which influences the availability of both of these basal organic matter sources is recycling of organic matter through the microbial loop (Azam et al. 1983). While largely recognised as a fundamental structural feature of the pelagic environment, recycled production, particularly recycled organic matter arising from production by chemosynthetic bacteria on organic deposits, is also a key feature of benthic marine food webs (Levin \& Michener 2002, MacAvoy et al. 2002). This pathway offers a stable and persistent source of organic matter for food webs and acts to increase the diversity of basal organic matter sources in a resource pool. The existence of recycled pathways for organic matter such as chemoautotrophic production raises a key question for understanding nutrition of coastal populations: How does variability in the diversity of basal organic matter sources across a landscape correspond with variability in resource use (niche breadth) among subpopulations in a metapopulation? Fjordic ecosystems offer an opportunity to resolve these patterns in nature as their complex topography and strong environmental gradients result in dramatic gradients in primary productivity (Burrell 1988, Goebel et al. 2005, Wing et al. 2007) and in the resulting availability of basal organic matter sources to food webs.

New Zealand's Fiordland marine ecosystem represents an ideal study system in this regard. A high incidence of invertebrate-chemoautotrophic symbioses has been observed within benthic communities of the innermost regions of the New Zealand fjords (McLeod et al. 2010b). In these habitats, standing stocks of macroalgae and phytoplankton are relatively low (Goebel et al. 2005, Wing et al. 2007). As an alternative resource base, recycling of organic matter by chemosynthesis, particularly from the chemosymbiont-bearing clam Solemya parkinsonii, plays an important role in nutrition of upper trophic level benthic fishes (Rodgers \& Wing 2008, McLeod et al. 2010a) and invertebrates (Jack et al. 2009). Organic matter may be recycled from both terrestrial and marine sources by chemoautotrophs. For example, chemosynthetic fixation of recycled organic matter from forest detritus supports between 38 and $51 \%$ of the food web utilised by benthic hagfish (McLeod \& Wing 2007). Thus, in some inner basin fjordic environments, recycled production may provide a majority of the organic matter to benthic food webs (McLeod et al. 2010b). In these habitats, chemoautotrophic production provides a basis for support of upper trophic level species and a mechanism for maintenance of subpopulations across strong productivity gradients.

Evidence from genetic (Perrin et al. 2004) and natural markers (Lawton et al. 2010) demonstrates that many invertebrate and coastal fish populations display strong spatial structure among the basins and across the productivity gradients of Fiordland (Wing 2009, Beer et al. 2011, Jack et al. 2011). In the case of blue cod Parapercis colias, there is evidence for source-sink structure of populations distributed between the wave-exposed outer coast kelp forest habitats and the quiescent basins of the inner fjords 
(Rodgers \& Wing 2008). Tagging studies have demonstrated low rates of unidirectional adult migrations from the outer coast into the inner fjord habitats, and a high degree of site fidelity (Carbines \& McKenzie 2004). Evidence from trace elemental signatures within the otoliths of these fish corroborate these findings and suggest that subpopulations in the inner fjords are distinct with a high degree of site fidelity (Beer et al. 2011). Due to the likelihood that chemoautotrophic production plays an important role in food web dynamics in these habitats, we investigated differences in use of basal organic matter sources and trophic position among subpopulations of blue cod distributed among outer coastal and inner fjord habitats in multiple fjords.

Analysis of stable isotope ratios of carbon ${ }^{13} \mathrm{C} /{ }^{12} \mathrm{C}$ and nitrogen ${ }^{15} \mathrm{~N} /{ }^{14} \mathrm{~N}$ offers a powerful tool for resolving basal organic matter sources supporting food webs and trophic level of consumers (Fry 2006). The ability to resolve sources relies on a consistent discrimination among basal organic matter pools (Cornelisen et al. 2007). Organic matter from chemoautotrophic production is an especially well resolved source because of a high level of isotopic fractionation of both carbon and nitrogen in chemosynthesis (Levin \& Michener 2002). In this case, carbon fixed in the Rubisco I pathway common to chemoautotrophic bacteria has $\delta^{13} \mathrm{C}$ of -27 to $-37 \%$, making it isotopically distinct from carbon fixed by macroalgae and phytoplankton, which generally has $\delta^{13} \mathrm{C}$ of $>-20 \%$ (Robinson \& Cavanaugh 1995). Nitrogen isotopic ratios also contain information on source pools but, unlike, carbon are strongly discriminated with each trophic level providing important information on the tropic position of consumers (Post 2002). These attributes of $\delta^{13} \mathrm{C}$ and $\delta^{15} \mathrm{~N}$ present a distinct scientific opportunity in the Fiordland system to distinguish between inputs of organic matter from photoautotrophic versus chemoautotrophic production to the food webs supporting blue cod Parapercis colias, an important high trophic level consumer. In this system, the chemosymbiontharbouring clam Solemya parkinsonii makes up a large component of the chemoautotrophic biomass (McLeod et al. 2010b) and is an important component of the diet of fishes and invertebrates (Rodgers \& Wing 2008, Jack et al. 2009).

In the present study we use stable isotope analysis and gut content analysis to resolve 2 important patterns in this system: (1) variability in the proportion of organic matter from chemosynthesis and trophic level for multiple fjordic subpopulations of blue cod, and (2) independent estimates of feeding on the chemosymbiont-bearing clam Solemya parkinsonii from dietary studies. These data provide the basis for assessing how subpopulations of blue cod distributed across multiple fjordic habitats respond to strong gradients in biomass of benthic and pelagic primary producers. We explicitly test whether fjordic populations are subject to greater individual variability in use of organic matter sources from chemosynthesis in the inner fjord habitats, where abundance of kelp and pelagic production are relatively low. These analyses form an important test of how spatially structured populations respond to a variable resource environment at the landscape scale $(\sim 200 \mathrm{~km})$.

\section{MATERIALS AND METHODS}

\section{Oceanographic survey}

Oceanographic data were collected from surveys conducted at all sites in 1998, 1999, 2002, 2003, 2005, 2006 and 2010. We collected fluorescence readings every $0.5 \mathrm{~s}$ from the surface to $50 \mathrm{~m}$ at each study site over a 12 yr period using a Seabird SBE 19 conductivity, temperature, and depth profiler (CTD) with an attached factory-calibrated Wetstar fluorometer. Calibration of the fluorometer was checked against chl a concentrations from water samples (Goebel et al. 2005). Data were post-processed to $0.5 \mathrm{~m}$ bins using standard Seabird processing algorithms for the pumped SBE 19. Data on average chl a concentration were calculated among years for each site and integrated values were calculated for a water column $1 \mathrm{~m}^{2}$ by $20 \mathrm{~m}$ deep.

\section{Abundance of Ecklonia radiata}

Density of the dominant stipitate kelp Ecklonia radiata was measured at each study site during surveys in 2003,2004, 2006 and 2010 using paired $2 \mathrm{~m}^{2}$ quadrats with 6 quadrat pairs sampled within depth strata centred at 5, 10 and $15 \mathrm{~m}$. Mean density and standard error (SE) were calculated as the hierarchical mean of means, and by depth, survey and site.

\section{Presence of mussels}

Photoquadrat surveys were carried out during 2006 and 2010 using a housed digital camera (Nikon D70 6.1 megapixel) mounted on a $0.17 \mathrm{~m}^{2}$ quadrat frame. Each survey was conducted by a scuba diver who randomly positioned 10 quadrats along $100 \mathrm{~m}$ within 
each depth stratum (centred on 0 and $2.5 \mathrm{~m}$ from mean high tide). The digital photos were postprocessed from each stratum using Nikon View 6.2.7 and Nikon Edit 6.2.7. Following post-processing, presence or absence of mussels (Mytilus edulis galloprovincialis, Aulacomya maoriana and Perna canaliculus) beds were determined at each site.

\section{Blue cod sample collection}

Blue cod were sampled in 2000, 2002, 2003, 2004 and 2009 at paired inner and outer fjord sites in Bradshaw Sound $(\mathrm{n}=31)$, Doubtful Sound $(\mathrm{n}=89)$, Breaksea Sound $(n=82)$, Dusky Sound $(n=100)$ and Long Sound-Preservation Inlet $(\mathrm{n}=111)$ (Fig. 1). An orthogonal sampling design was employed with all samples collected during austral spring (October to November), using hand lines with artificial lures and size 6/0 hooks to target adults and reduce by-catch (Carbines 1999). Fish were euthanised before being measured $( \pm 1 \mathrm{~mm}$ total length, TL) and weighed (whole blotted wet weight, WW). Stomachs were removed and fixed in $10 \%$ formalin solution buffered with seawater.

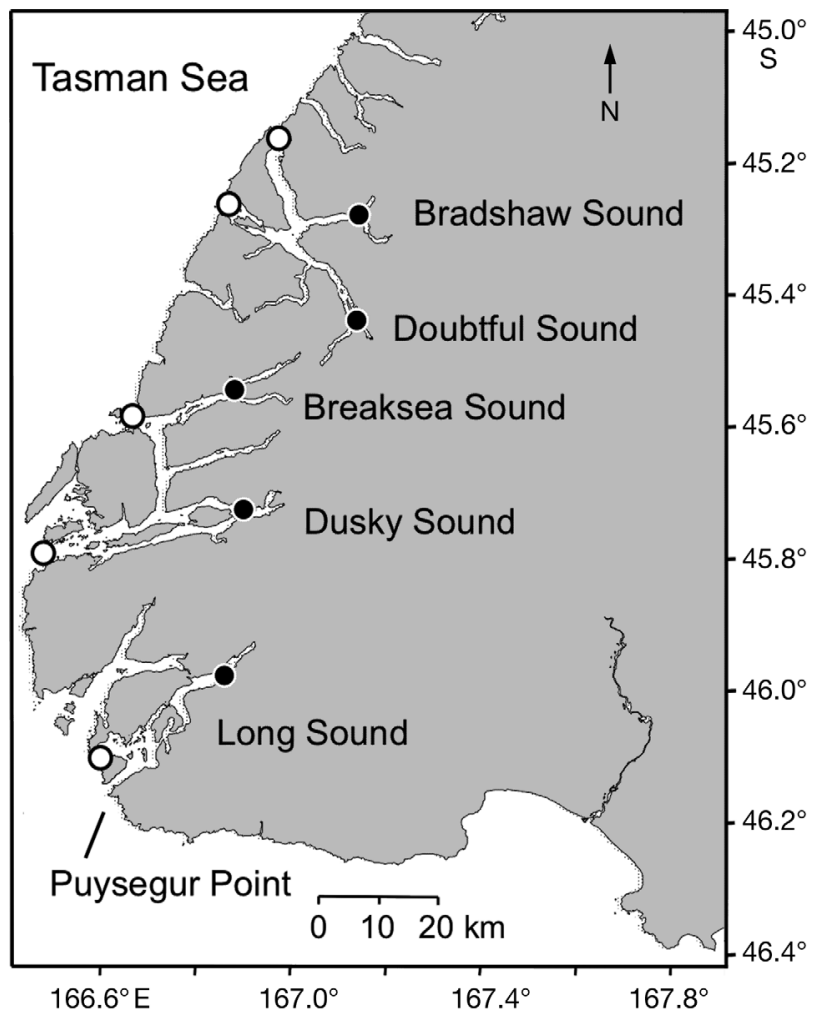

Fig. 1. Fiordland showing study sites: $\bullet=$ inner fjord locations, entrance or $\mathrm{O}=$ open coastal locations

\section{Stable isotope analysis}

Muscle tissue samples were removed from the left dorsolateral side of each fish shortly after capture and oven dried at $\sim 60^{\circ} \mathrm{C}$. Samples were then ground to a fine powder using mortar and pestle. From each muscle sample, a $1 \mathrm{mg}$ subsample was weighed and sealed into a tin capsule for stable isotope analysis of $\delta^{13} \mathrm{C}$ and $\delta^{15} \mathrm{~N}$. Samples were analysed in the Department of Chemistry, University of Otago on a Europa 20-20 update stable isotope mass spectrometer (Europa Scientific) interfaced with a Carlo Erba elemental analyzer (NA1500) in continuous flow mode (precision: $0.2 \%$ for $\delta^{13} \mathrm{C}, 0.3 \%$ for $\delta^{15} \mathrm{~N}$ ). Precision was defined as 1 $\mathrm{SD}$ of replicates of laboratory standards. Primary standards for analysis were calibrated to EDTA laboratory standard reference (Elemental Microanalysis) and standardised against international standards (IAEACH-6 for carbon, IAEAN1 and IAEAN2 for nitrogen). The primary standard for $\delta^{15} \mathrm{~N}$ was atmospheric air and for $\delta^{13} \mathrm{C}$ was Peedee belemnite limestone.

\section{Isotopic mixing models and trophic level}

Spatial variation in $\delta^{15} \mathrm{~N}$ and $\delta^{13} \mathrm{C}$ of phytoplankton samples is generally low in this system; thus, the stable isotopic signature of phytoplankton was characterised by sampling suspended particulate organic matter (SPOM) during a phytoplankton bloom (Wing et al. 2008). In contrast, the ecophysiology of the dominant stipitate kelp Ecklonia radiata varies along the fjord axis relative to topographic shading and wave exposure (Wing et al. 2007) and spatial patterns in $\delta^{15} \mathrm{~N}$ and $\delta^{13} \mathrm{C}$ in the dominant estuarine algae Ulva pertusa vary with nutrient source pools and along physical gradients (Cornelisen et al. 2007). Due to this, a weighted aggregate isotopic signature for estuarine algae and macroalgae from the underlying seawater layer was used, which incorporated variation in species composition and isotopic signatures along the fjord axis (after Wing et al. 2008) (see Fig. 2). A combined isotopic signature for photoautotrophic production was calculated by averaging $\delta^{13} \mathrm{C}$ and $\delta^{15} \mathrm{~N}$ of SPOM and macroalgae $\left(\delta^{13} \mathrm{C}:-19.66 \%\right.$ [0.19], $\delta^{15} \mathrm{~N}: 5.65 \%$ [0.39]). An estimate for $\delta^{13} \mathrm{C}$ and $\delta^{15} \mathrm{~N}$ (mean $\pm \mathrm{SE}$ ) of chemoautotrophic production was based on McLeod et al. (2010b), where $\delta^{13} \mathrm{C}=-30.55 \pm 0.04 \%$ and $\delta^{15} \mathrm{~N}=$ $-5.02 \pm 0.23 \%$ for common chemoautotrophs in Fiordland (see Fig. 2). 
Although many studies have used both $\delta^{13} \mathrm{C}$ and $\delta^{15} \mathrm{~N}$ to estimate mixtures of organic matter sources, this approach may be sensitive to natural variability in trophic discrimination factors $\left(\Delta^{13} \mathrm{C}\right.$ and $\Delta^{15} \mathrm{~N}$ ) within food webs (Newsome et al. 2010). Results of mass balance analyses are particularly sensitive to variability in $\Delta^{15} \mathrm{~N}$, which is large relative to variability in $\Delta{ }^{13} \mathrm{C}$. In the present analysis, we take a conservative approach to reduce this major source of uncertainty by using only $\delta^{13} \mathrm{C}$ to estimate contribution of photoautotrophic versus chemoautotrophic source pools after Phillips \& Gregg (2001). We note that the large separation in $\delta^{13} \mathrm{C}$ of these source pools outweighs uncertainty in $\Delta^{13} \mathrm{C}$ with the food web (sensu McLeod \& Wing 2007). Our analysis of trophic level then relies on information from $\delta^{15} \mathrm{~N}$, which has a relatively large trophic discrimination factor. As we estimated change in $\delta^{15} \mathrm{~N}$ from a mixture of organic matter sources, we first estimated $\delta^{15} \mathrm{~N}_{\text {base }}$ according to the mass balance analysis of organic matter source pools, chemoautotrophic versus photoautotrophic. Trophic level was calculated after Post (2002) for each blue cod from $\delta^{15} \mathrm{~N}_{\text {base, }}$ defined as: $\left(\delta^{15} \mathrm{~N}_{\text {consumer }}\right.$ $\left.-\delta^{15} \mathrm{~N}_{\text {base }} / \Delta^{15} \mathrm{~N}\right)+1$. As Parapercis colias feeds at a relatively high trophic level (4 to 5 ) and $\Delta^{15} \mathrm{~N}$ is averaged over 4 to 5 steps, uncertainty in this estimate was reduced (sensu Vander Zanden \& Vadeboncoeur 2002). We used 2 average trophic discrimination factors reported for aquatic environments after McCutchan et al. (2003) (+0.4 $\pm 0.17 \%$ for $\Delta^{13} \mathrm{C}$, and $+2.3 \pm 0.28 \%$ for $\Delta^{15} \mathrm{~N}$ ).

\section{Stomach content analysis}

Fixed stomach contents were rinsed over a $500 \mu \mathrm{m}$ mesh and transferred to a $70 \%$ ethanol solution. Prey items were sorted for presence of Solemya parkinsonii under a dissecting stereomicroscope and the blotted wet weight was recorded. This was then expressed as a percentage of the total wet body weight of each fish $(\% \mathrm{BW})$.

\section{Statistical analysis}

Resemblance matrices based on Euclidean distances among samples were calculated for $\delta^{13} \mathrm{C}$, $\delta^{15} \mathrm{~N}$, trophic level and proportion of chemosynthetic organic matter for each blue cod. A permutational analysis of variance (PERMANOVA) (Anderson et al. 2008), using Type III partial sums of squares and unrestricted permutations of raw data, was used to test for univariate differences in each parameter among pairs of inner and outer sites for each fjord.

A distance-based test for homogeneity of multivariate dispersion (PERMDisp) was then used to test for differences in dispersion of $\delta^{13} \mathrm{C}$ and $\delta^{15} \mathrm{~N}$, and in dispersion of trophic level and proportion of chemosynthetic organic matter for blue cod among pairs of sites for each fjord. Data were normalised and a resemblance matrix was calculated based on Euclidean distances. PERMDisp was then used to test for significant deviations from the multivariate centroid for each pair of sites.

A general linear model (JMP V 7.0, SAS) was used to test for covariance between proportion of chemosynthetic organic matter and (1) density of Ecklonia radiata, (2) concentration of $\mathrm{chl} a$ in the water column and (3) presence of mussel beds among study sites.

\section{RESULTS}

\section{Isotopic mixing models and trophic level}

Results of univariate PERMANOVA for pair-wise comparisons indicated that $\delta^{13} \mathrm{C}$ and $\delta^{15} \mathrm{~N}$ of blue cod muscle tissue differed among sites within Bradshaw and Doubtful Sounds (Table 1). This pattern indicated a higher proportion of organic matter originating from chemoautotrophy at inner fjord sites in Bradshaw and Doubtful Sound (Table 2, Figs. 2, 3 \& 4a). In Dusky Sound, blue cod from the outer site fed at higher trophic levels than those from the inner fjord site (Table 2, Fig. 3). Distancebased tests for homogeneity of multivariate dispersions indicated larger dispersion in $\delta^{13} \mathrm{C}$ and $\delta^{15} \mathrm{~N}$,
Table 1. Parapercis colias. Permutational analysis of variance (PERMANOVA) results for blue cod $\delta^{13} \mathrm{C}$, and $\delta^{15} \mathrm{~N}$, and distance-based tests for homogeneity of multivariate dispersion (PERMDisp) of $\delta^{13} \mathrm{C}$ and $\delta^{15} \mathrm{~N}$. Bold p-values: significant differences relative to POSITION within each fjord

\begin{tabular}{|c|c|c|c|c|c|c|c|}
\hline \multirow{2}{*}{ Fjord } & \multirow[t]{2}{*}{ df } & \multicolumn{2}{|c|}{$-\delta^{13} \mathrm{C}-$} & \multicolumn{2}{|c|}{$-\delta^{15} \mathrm{~N}-$} & \multicolumn{2}{|c|}{ PERMDisp } \\
\hline & & $t$ & $\mathrm{p}$ & $t$ & $\mathrm{p}$ & $F$ & $\mathrm{p}$ \\
\hline Bradshaw & 1,29 & 2.92 & 0.006 & 2.15 & 0.04 & 17.5 & 0.0003 \\
\hline Doubtful & 1,68 & 4.45 & 0.00001 & 5.38 & 0.0001 & 55.15 & 0.0001 \\
\hline Breaksea & 1,70 & 0.04 & 0.97 & 1.32 & 0.19 & 2.65 & 0.14 \\
\hline Dusky & 1,94 & 0.31 & 0.77 & 1.85 & 0.07 & 16.98 & 0.0001 \\
\hline Long & 1,93 & 3.19 & 0.0005 & 1.43 & 0.16 & 1.64 & 0.36 \\
\hline
\end{tabular}


Table 2. Parapercis colias. Permutational analysis of variance (PERMANOVA) results for blue cod proportion of chemoautotrophic organic matter (Chem. OM) and trophic level (Troph.), and distance-based tests for homogeneity of multivariate dispersion (PERMDisp). Bold p-values: significant differences relative to POSITION within each fjord

\begin{tabular}{|lcccccccc|}
\hline \multirow{2}{*}{ Fjord } & \multirow{2}{*}{$\mathrm{df}$} & \multicolumn{2}{c}{ Chem. OM } & \multicolumn{2}{c}{ Troph. } & \multicolumn{2}{c}{ PERMDisp } \\
& & $t$ & $\mathrm{p}$ & $t$ & $\mathrm{p}$ & $F$ & $\mathrm{p}$ \\
\hline Bradshaw & 1,29 & 6.33 & $\mathbf{0 . 0 1 3}$ & 0.096 & 0.76 & 11.07 & $\mathbf{0 . 0 0 4}$ \\
Doubtful & 1,68 & 20.53 & $\mathbf{0 . 0 0 0 0 3}$ & 2.83 & 0.097 & 26.90 & $\mathbf{0 . 0 0 0 1}$ \\
Breaksea & 1,70 & 0.045 & 0.84 & 1.74 & 0.19 & 3.05 & 0.13 \\
Dusky & 1,94 & 0.71 & 0.42 & 4.42 & $\mathbf{0 . 0 3}$ & 14.41 & $\mathbf{0 . 0 0 0 4}$ \\
Long & 1,93 & 2.26 & 0.14 & 0.55 & 0.45 & 1.09 & 0.46 \\
\hline
\end{tabular}

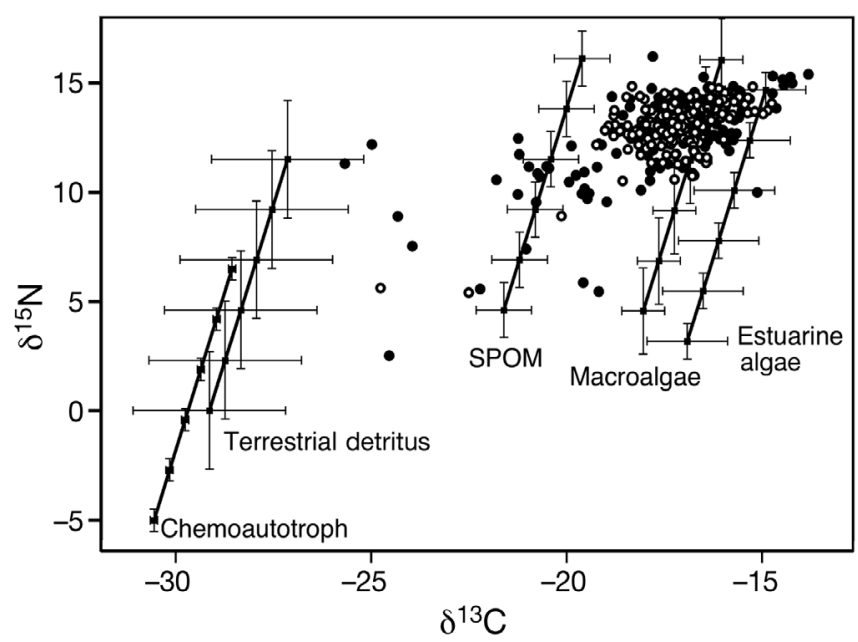

Fig. 2. Parapercis colias. $\delta^{13} \mathrm{C}$ and $\delta^{15} \mathrm{~N}$ for individual blue cod from inner fjord $(0)$ and entrance or open coastal $(O)$ locations. $\delta^{13} \mathrm{C}$ and $\delta^{15} \mathrm{~N}$ of basal organic matter sources are plotted with a successive addition of the average trophic discrimination factors, $\Delta^{13} \mathrm{C}(+0.4)$ and $\Delta^{15} \mathrm{~N}(+2.3)$ after $\mathrm{Mc}-$ Cutchan et al. (2003). SPOM = suspended particulate organic matter. Means $\pm 1 \mathrm{SD}$

and in the proportion of chemosynthetic organic matter and trophic level at inner fjord sites at Bradshaw, Doubtful and Dusky Sounds compared with dispersion within outer coast sites in these same fjords (Tables $1 \& 2$, Figs. $2 \& 3$ ). There were no significant differences in length or weight of fish among sites in these analyses.

\section{Stomach content analysis}

Solemya parkinsonii was present in the stomach contents of blue cod from the inner fjord sites of Doubtful, Breaksea and Dusky Sound and a small fraction of fish in the outer coastal site in Long Sound (Fig. 4b).

\section{Gradients in standing stock of primary producers}

Results of the general linear model for proportion of chemosynthetic organic matter statistically explained by the variables (1) concentration of chl $a$ and (2) occurrence of mussels indicate significant correlation of variability in organic matter composition with presence of mussel beds and concentration of $\mathrm{chl} \mathrm{a}\left(\mathrm{r}^{2}=0.87\right.$, $F_{3,6}=13.07, \mathrm{p}=0.005$ ) (Table 3, Fig. 5). The proportion of chemosynthetic organic matter used in food webs fed on by blue cod was higher in regions with low chl $a$ or at sites where mussel beds were absent. Density of Ecklonia radiata was included in this statistical model, but had a non-significant correlation with proportion of chemosynthetic organic matter (Table 3).

\section{DISCUSSION}

The data and results presented here demonstrate that subpopulations of blue cod Parapercis colias within inner-fjordic habitats rely more heavily on food webs supported by chemosynthesis in some, but not all, of the fjords studied. Further, use of organic matter from chemosynthesis was correlated with a scarcity in the available biomass of pelagic primary producers, as indicated by chl $a$, as well as the occurrence of mussels, which are key to benthic-pelagic coupling in the system (Wing \& Leichter 2011). These data suggest that benthic food webs supported by chemoautotrophic-derived organic matter provide an alternative resource base for blue cod subpopulations in fjordic habitats when labile photoautotrophic sources become scarce.

Evidence for this comes from several patterns in the data. Individual estimates of trophic level and proportion of chemosynthetic organic matter indicate that subpopulations in the inner fjord habitats of Bradshaw, Doubtful and Dusky Sounds varied more greatly in resource use among individuals than those at outer coastal sites. In these habitats, individual blue cod fed within food webs with up to 61,76 and $66 \%$ of organic matter originating from chemoautotrophy respectively. Average use of organic matter from chemoautotrophy by blue cod subpopulations in these food webs was $13 \%$ for Bradshaw, $24 \%$ for Doubtful and 8\% for Dusky Sound. These patterns are consistent with a systematic response by individ- 


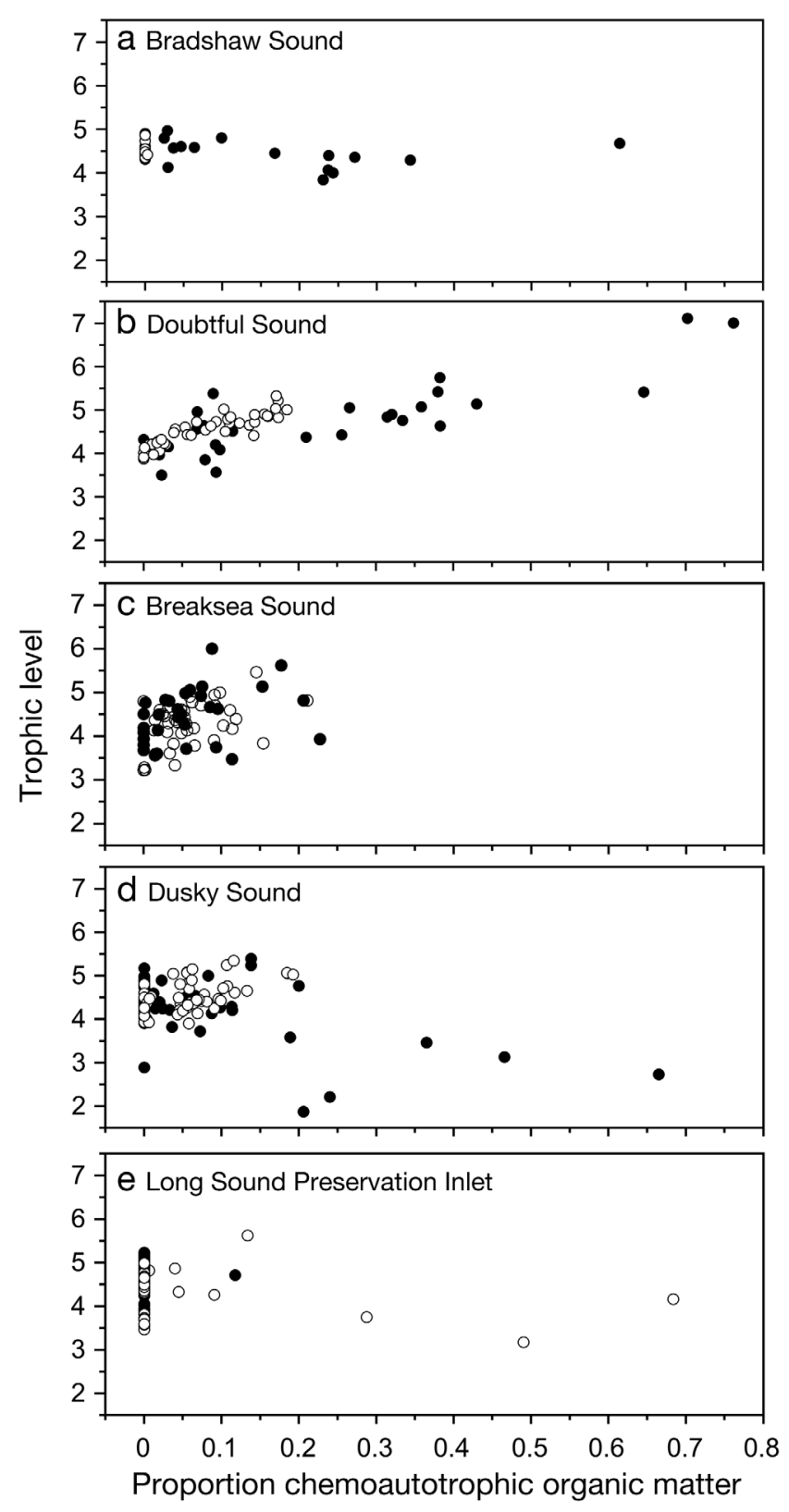

Fig. 3. Parapercis colias. Individual values for trophic level and proportion of organic matter obtained from chemoautotrophic production for pairs of inner $(\bullet)$ and outer $(O)$ fjord sites

uals occupying the inner fjord habitats to feeding on chemosynthesis-based food webs. At some inner fjord sites, we observed a high incidence of the chemosymbiont-bearing clam Solemya parkinsonii in the stomachs of blue cod, suggesting that blue cod actively feed in the thick layers of decomposing forest material common in these relatively low productivity habitats (McLeod et al. 2010b). Evidence for migration of individuals from outer coastal to inner

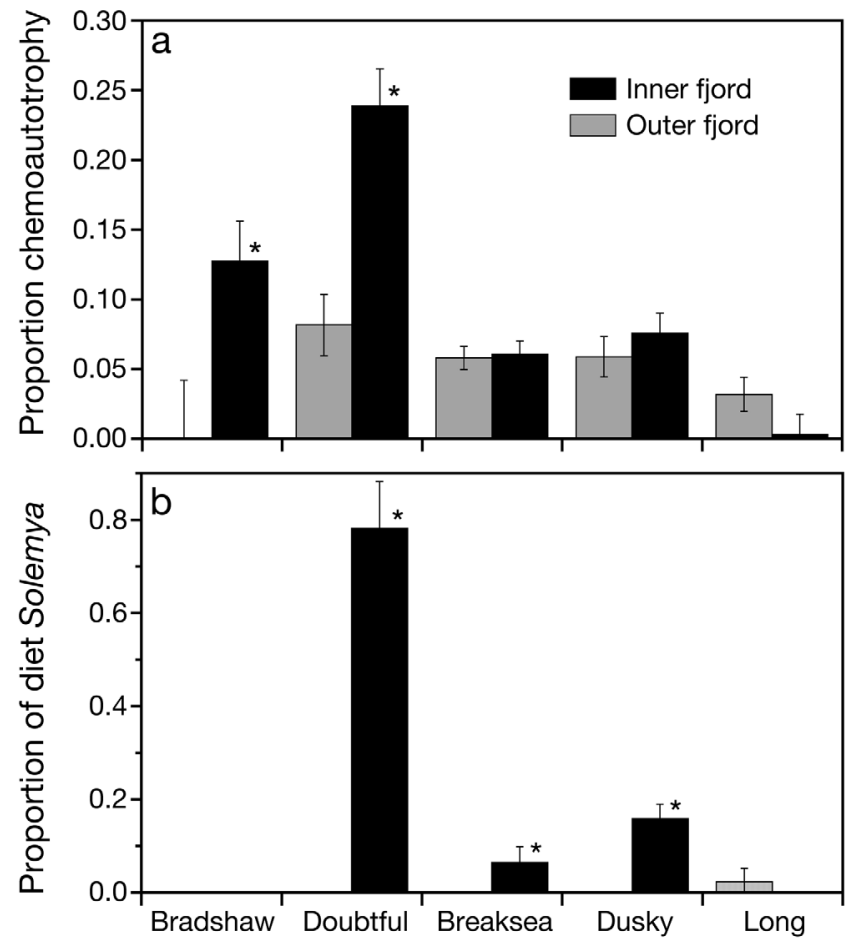

Fig. 4. Parapercis colias. (a) Estimates of proportion of organic matter obtained from chemoautotrophic production and (b) proportion of diet by weight consisting of Solemya parkinsonii, from inner and outer fjord sites. Means $\pm 1 \mathrm{SE}$. *: significant differences within fjords

Table 3. General linear model for the fraction of organic matter originating from chemoautotrophic production versus concentration of chl $a$, density of Ecklonia radiata and presence of mussels $\left(r^{2}=0.87, F_{3,6}=13.07, p=0.005\right)$. Significant p-values in bold. Proportion chemoautotrophy $=E$ Ck-

lonia(0.005) - chl a (0.002) - mussel bed(0.203)+ 0.387

\begin{tabular}{|lcc|}
\hline Factor & Estimate & $\mathrm{p}>|t|$ \\
\hline Intercept & 0.39 & $\mathbf{0 . 0 0 0 8}$ \\
Presence of mussel beds & -0.20 & $\mathbf{0 . 0 0 1 1}$ \\
Ecklonia radiata density & 0.005 & 0.64 \\
Concentration chl $a$ & -0.002 & $\mathbf{0 . 0 3 4}$ \\
\hline
\end{tabular}

fjord habitats is consistent with this observed variability in organic matter use, and some of the individual variability in organic matter use may reflect habitat switching during migration (Rodgers \& Wing 2008).

Chemosynthesis-fuelled benthic communities offer an alternative food source in the fjord habitats where phytoplankton biomass is low or less available. For example, Jack et al. (2009) observed that in the inner reaches of Doubtful Sound where bivalves were rare, and therefore benthic-pelagic coupling relatively low, red rock lobsters Jasus edwardsii had systemat- 

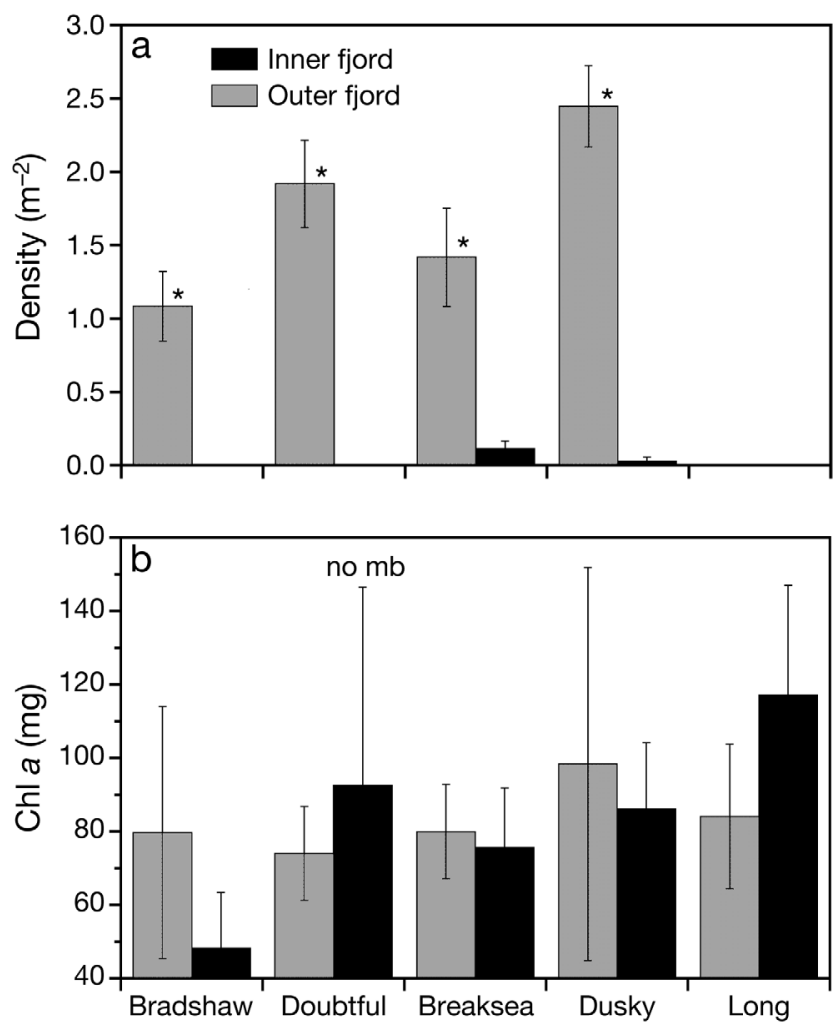

Fig. 5. (a) Density of Ecklonia radiata and (b) chl a in a $20 \mathrm{~m}^{3}$ column of water. Means \pm 1 SE. no mb: location lacking mussel beds. *Significant differences within fjords

ically shifted toward higher use of organic matter originating from chemoautotrophy. A similar pattern has been observed in diet of the generalist wrasse Notolabrus celidotus (McLeod et al. 2010a, Davis \& Wing 2012). Together, the observed patterns highlight the importance of both high biomass of primary producers and intact food web structure in the provision of organic matter to food webs supporting high trophic level species.

The role of chemoautotrophic production in the benthic food web was variable among fjords. We obtained evidence for incorporation of chemoautotrophically derived organic matter in food webs used by individual blue cod within inner fjord habitats in Bradshaw, Doubtful and Dusky Sounds and at the outer coastal site in Long Sound (Preservation Inlet), but not within Breaksea Sound. This was largely consistent with our observations of variability in the standing biomass of pelagic primary producers in the inner fjord habitats, as indicated by patterns in chl $a$. Long term patterns in chl a indicated low standing stock of phytoplankton in Bradshaw Sound and intermediate levels in Dusky and Breaksea Sounds. In Doubtful Sound, the lack of significant populations of bivalves likely reduced availability of organic matter from pelagic production through the associated low benthic-pelagic coupling in this region (Wing \& Leichter 2011). In Long Sound, a high standing stock of phytoplankton, as indicated by high long-term

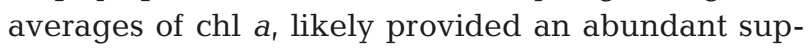
ply of labile organic matter from pelagic production to benthic food webs.

While the data and results presented here indicate distinct differences in variability of resource use among subpopulations of blue cod, there are several caveats that must accompany our conclusions. Our data and analyses are correlative in nature, and while each of the mechanisms that we have suggested are consistent with patterns observed in the field, we have not performed manipulative experiments to explicitly test these ideas. Nevertheless, the Fiordland landscape offers an ideal natural experimental system with multiple gradients in primary production across which to make observations. The result is a replicated test of the coherence between variability in use of basal organic matter sources and standing stock of primary producers. Our data on individual variability in the use of organic matter sources and in trophic level represent integrations of diet for each individual as recorded by $\delta^{15} \mathrm{~N}$ and $\delta^{13} \mathrm{C}$ in the low lipid content muscle tissue of each fish (Rodgers \& Wing 2008). Half-lives of $\delta^{15} \mathrm{~N}$ and $\delta^{13} \mathrm{C}$ in muscle tissue of fish, and blue cod in particular, may approach a year or more (Hesslein et al. 1993, Suring \& Wing 2009). Therefore, patterns in organic matter use and trophic level reported here reflect a longterm integration of habitat use for each individual, including migrations among habitats. Further, our ability to accurately estimate proportion of organic matter source pools with mass balance of $\delta^{13} \mathrm{C}$ and trophic level with trophic discrimination of $\delta^{15} \mathrm{~N}$ rely on (1) isotopic discrimination of organic matter source pools and (2) estimates of trophic discrimination factors $\left(\Delta^{13} \mathrm{C}\right.$ and $\left.\Delta \Delta^{15} \mathrm{~N}\right)$ within the system. The first criterion is met by fine scale spatial and temporal sampling of source pools in the system (e.g. Cornelisen et al. 2007, McLeod \& Wing 2009). The second criterion is met by using a mean value for $\Delta^{15} \mathrm{~N}$ reported for aquatic systems (McCutchan et al. 2003), and by the observation that variance in $\Delta^{15} \mathrm{~N}$ becomes constrained at the higher trophic levels observed for blue cod (e.g. Vander Zanden \& Vadeboncoeur 2002).

The data and results presented here have important implications for understanding mechanisms for maintenance of marine metapopulations distributed across habitat patches with distinct differences in 
productivity and availability of resources. In the present example, subpopulations of blue cod inhabiting fjordic habitats with relatively low standing stocks of benthic and pelagic primary producers display greater dispersion among individuals in the use of basal organic matter sources. The clear spatial patterns in reliance on chemoautotrophic production indicate that chemoautotrophy fuels a large component of the food web in these environments. This provides an important mechanism for maintenance of a resource base for upper trophic level populations, such as Parapercis colias, across the intense gradients in productivity of fjordic environments. The existence of a recycled pathway for relatively refractory organic matter in this case provides an important alternative source of organic matter fuelling food webs to support high trophic level consumers in these marginal habitats.

Acknowledgements. We thank S. Lusseau, K. Rodgers, J. Davis, B. Walker, B. Dickson and P. Hesseltine for their assistance with sample collection. R. van Hale and R. Frew assisted with chemical analysis. Support was provided by a Marsden Grant from the Royal Society of New Zealand to S.R.W. (UoO-00213), a Hutton Fund Grant to N.A.B., and by the Commonwealth Scholarship and Fellowship Plan (N.A.B., L.J.).

\section{LITERATURE CITED}

Anderson M, Gorley R, Clarke K (2008) PERMANOVA+ for PRIMER: Guide to software and statistical methods. University of Auckland, Auckland

Azam F, Fenchel T, Field J, Gray J, Meyer-Reil L, Thingstad $\mathrm{F}$ (1983) The ecological role of water-column microbes in the sea. Mar Ecol Prog Ser 10:257-263

> Beer NA, Wing SR, Swearer SE (2011) Otolith elemental evidence for spatial structuring in a exploited temperate reef fish population. Mar Ecol Prog Ser 442:217-227

> Bolnick DI, Svanbäck R, Fordyce JA, Yang LH, Davis JM, Hulsey CD, Forister ML (2003) The ecology of individuals: incidence and implications of individual specialization. Am Nat 161:1-28

Burrell DC (1988) Carbon flow in fjords. Oceanogr Mar Biol Annu Rev 26:143-226

Carbines G (1999) Large hooks reduce catch-and-release mortality of blue cod Parapercis colias in the Marlborough Sounds of New Zealand. N Am J Fish Manag 19: 992-998

Carbines G, McKenzie J (2004) Movement patterns and stock mixing of blue cod in Dusky Sound in 2002. Ministry of Fisheries, Wellington

> Cornelisen CD, Wing SR, Clark KL, Bowman MH, Frew RD, Hurd CL (2007) Patterns in $\delta^{13} \mathrm{C}$ and $\delta^{15} \mathrm{~N}$ signatures of Ulva pertusa: Interaction between physical gradients and nutrient source pools. Limnol Oceanogr 52:820-832

> Davis JP, Wing SR (2012) Niche partitioning in the Fiordland wrasse guild. Mar Ecol Prog Ser 446:207-220
Doak DF, Bigger D, Harding EK, Marvier MA, O'Malley RE, Thomson D (1998) The statistical inevitability of stabilitydiversity relationships in community ecology. Am Nat 151:264-276

Fry B (2006) Stable isotope ecology. Springer, New York, NY Fry B, Mumford P, Tam F, Fox D, Warren G, Havens K, Steinman A (1999) Trophic position and individual feeding history of fish from Lake Okeechobee, Florida. Can J Fish Aquat Sci 56:590-600

> Goebel N, Wing S, Boyd P (2005) A mechanism for onset of diatom blooms in a fjord with persistent salinity stratification. Estuar Coast Shelf Sci 64:546-560

Gust N, Choat J, Ackerman J (2002) Demographic plasticity in tropical reef fishes. Mar Biol 140:1039-1051

> Hesslein R, Hallard K, Ramlal P (1993) Replacement of sulfur, carbon, and nitrogen in tissue of growing broad whitefish (Coregonus nasus) in response to a change in diet traced by $\delta^{34} \mathrm{~S}, \delta^{13} \mathrm{C}$ and $\delta^{15} \mathrm{~N}$. Can J Fish Aquat Sci 50:2071-2076

> Jack L, Wing SR (2010) Maintenance of old-growth size structure and fecundity of the red rock lobster Jasus edwardsii among marine protected areas in Fiordland, New Zealand. Mar Ecol Prog Ser 404:161-172

Jack L, Wing SR (2011) Individual variability in trophic position and diet of a marine omnivore is linked to kelp bed habitat. Mar Ecol Prog Ser 443:129-139

Jack L, Wing SR, McLeod RJ (2009) Prey base shifts in red rock lobster Jasus edwardsii in response to habitat conversion in Fiordland marine reserves: implications for effective spatial management. Mar Ecol Prog Ser 381: 213-222

> Jack L, Wing SR, Hu Y, Roberts M (2011) Natural trace elemental markers for adult red rock lobsters Jasus edwardsii vary among replicate distinct water masses. Mar Ecol Prog Ser 443:141-151

> Lawton R, Wing S, Lewis AM (2010) Evidence for discrete subpopulations of sea perch (Helicolenus percoides) across four fiords in Fiordland, New Zealand. NZ J Mar Freshw Res 44:309-322

> Levin L, Michener R (2002) Isotopic evidence for chemosynthesis-based nutrition of macrobenthos: the lightness of being at Pacific methane seeps. Limnol Oceanogr 47: 1336-1345

Liu J, Hull V, Morzillo A, Wiens J (2011) Sources, sinks and sustainability. Cambridge University Press, Cambridge

MacAvoy SE, Carney RS, Fisher CR, Macko SA (2002) Use of chemosynthetic biomass by large, mobile, benthic predators in the Gulf of Mexico. Mar Ecol Prog Ser 225: $65-78$

McCutchan JH Jr., Lewis WM Jr., Kendall C, McGrath CC (2003) Variation in trophic shift for stable isotope ratios of carbon, nitrogen, and sulfur. Oikos 102:378-390

> McLeod RJ, Wing SR (2007) Hagfish in the New Zealand fjords are supported by chemoautotrophy of forest carbon. Ecology 88:809-816

$>$ McLeod R, Wing S (2009) Strong pathways for incorporation of terrestrially derived organic matter into benthic communities. Estuar Coast Shelf Sci 82:645-653

McLeod R, Wing S, Davis J (2010a) Habitat conversion and species loss alters the composition of carbon sources to benthic communities. Mar Ecol Prog Ser 411:127-136

McLeod R, Wing S, Skilton J (2010b) High incidence of invertebrate-chemoautotrophic symbioses supports the macro-infaunal community in the New Zealand fjords. Limnol Oceanogr 55:2097-2106 
Newsome SD, Bentall GB, Tinker MT, Oftedal OT, Ralls K, Estes JA, Fogel ML (2010) Variation in $\delta^{13} \mathrm{C}$ and $\delta^{15} \mathrm{~N}$ diet-vibrissae trophic discrimination factors in a wild population of California sea otters. Ecol Appl 20: 1744-1752

Oksanen T (1990) Exploitation ecosystems in heterogeneous habitat complexes. Evol Ecol 4:220-234

$>$ Oksanen L, Fretwell S, Arruda J, Niemela P (1981) Ecosystems in gradients of primary productivity. Am Nat 118: 240-261

Perrin C, Wing S, Roy M (2004) Population genetic structure amongst populations of the sea star Coscinasterias muricata in the New Zealand fjords. Mol Ecol 13:2183-2195

Phillips D, Gregg J (2001) Uncertainty in source partitioning using stable isotopes. Oecologia 127:171-179

Post D (2002) Using stable isotopes to estimate trophic position: models, methods, and assumptions. Ecology 83: 703-718

Pulliam H (1988) Sources, sinks, and population regulation. Am Nat 132:652-661

Robinson J, Cavanaugh C (1995) Expression of form I and II Rubisco in chemoautotrophic symbioses: Implications for the interpretation of stable carbon isotopic values. Limnol Oceanogr 40:1496-1502

Rodgers KL, Wing SR (2008) Spatial structure and movement of blue cod Parapercis colias in Doubtful Sound, New Zealand, inferred from $\delta^{13} \mathrm{C}$ and $\delta^{15} \mathrm{~N}$. Mar Ecol Prog Ser 359:239-248

Sanford E, Menge B (2007) Reproductive output and consistency of source populations in the sea star Pisaster ochraceus. Mar Ecol Prog Ser 349:1-12

Editorial responsibility: Jana Davis, Annapolis, Maryland, USA
Suring E, Wing SR (2009) Isotopic turnover rate and fractionation in multiple tissues of red rock lobster (Jasus edwardsii) and blue cod (Parapercis colias): consequences for ecological studies. J Exp Mar Biol Ecol 370:56-63

$>$ Tilman D, Lehman C, Thomson K (1997) Plant Diversity and ecosystem productivity: theoretical considerations. Proc Natl Acad Sci USA 94:1857-1861

Vander Zanden HB, Bjorndal KA, Reich KJ, Bolten AB (2010) Individual specialists in a generalist population: results from a long-term stable isotope series. Biol Lett 6: 711-714

- Vander Zanden M, Vadeboncoeur Y (2002) Fishes as integrators of benthic and pelagic food webs in lakes. Ecology 83:2152-2161

> Wing SR (2009) Decadal-scale dynamics of sea urchin population networks in Fiordland, New Zealand are driven by juxtaposition of larval transport against benthic productivity gradients. Mar Ecol Prog Ser 378:125-134

Wing SR, Leichter JJ (2011) Variation in environmental conditions in a subtidal prey refuge: effects of salinity stress, food availability and predation on mussels in a fjord system. Mar Ecol Prog Ser 422:201-210

> Wing S, Leichter J, Perrin C, Rutger S, Bowman M, Cornelisen C (2007) Topographic shading and wave exposure influence morphology and ecophysiology of Ecklonia radiata (C. Agardh 1817) in Fiordland, New Zealand. Limnol Oceanogr 52:1853-1864

> Wing SR, McLeod RJ, Clark KL, Frew RD (2008) Plasticity in the diet of two echinoderm species across an ecotone: microbial recycling of forest litter and bottom-up forcing of population structure. Mar Ecol Prog Ser 360:115-123

Submitted: December 1, 2011; Accepted: July 5, 2012 Proofs received from author(s): October 4, 2012 